\title{
Effect of Time of Day on the Magnitude of Stature Change Response Variability in Participants with Chronic Low Back Pain on Consecutive 2 Days
}

\author{
Pongsatorn Saiklang ${ }^{1}$, Rungthip Puntumetakul,", \\ Wantana Siritaratiwat ${ }^{2}$ and Rose Boucaut ${ }^{3,4}$
}

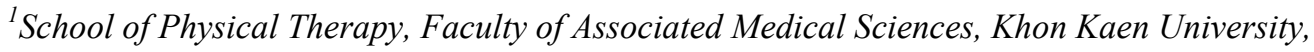 \\ Khon Kaen 40002, Thailand \\ ${ }^{2}$ Research Center in Back, Neck, Other Joint Pain and Human Performance (BNOJPH), \\ Faculty of Associated Medical Sciences, Khon Kaen University, Khon Kaen 40002, Thailand \\ ${ }^{3}$ Allied Health and Human Performance, University of South Australia, Adelaide, SA 5001, Australia \\ ${ }^{4}$ International Centre for Allied Health Evidence, University of South Australia, Adelaide, Australia
}

('Corresponding author's e-mail: rungthiprt@gmail.com)

Received: 9 July 2020, Revised: 23 May 2021, Accepted: 31 May 2021

\begin{abstract}
Measurements of stature change have been used to compare spinal loading in the sitting posture. However, it is difficult to interpret whether the stature change response recorded is truly due to an intervention or to the natural fluctuation of stature change response between the days. The aim of this study was to investigate the effect of time of day (morning and afternoon) on the variability of stature change in participants with chronic low back pain (CLBP) on 2 consecutive days. Forty-four participants with CLBP attended 2 sessions (morning and afternoon) of stature change testing on 4 separate days. A stature change response of more than $0.985 \mathrm{~mm}$ in the morning and $1.149 \mathrm{~mm}$ in the afternoon on 2 consecutive days indicates that an intervention itself has influenced stature change measurement in CLBP participants. The magnitude of stature change response on different days and times of day established specific levels of natural variation meaning changes above these levels can be attributed to intervention effects in participants with CLBP.
\end{abstract}

Keywords: Diurnal variation, Spinal loading, Seated stadiometer, Stature loss, Stature recovery

\section{Introduction}

Low back pain (LBP) is a major musculoskeletal disorder, with a prevalence of LBP up to $83.1 \%$ in various occupations [1-3]. Regarding sedentary work, office workers reported a prevalence of LBP between 30 - $61 \%$ [2-4]. Chronic low back pain (CLBP) has a worldwide prevalence of $11-25 \%$ among people that suffer from LBP [5-7]. The socioeconomic burden of CLBP stems from prolonged loss of function that consequently results in decreased work productivity and medical costs $[6,8,9]$.

Sitting is a regular activity for the working-age population who have sedentary jobs [10,11]. Prolonged sitting partly attributes to load on the lumbar disc $[12,13]$. With evidence that pathological changes in the spine arise from sitting $[13,14]$, measurement of stature change is important in the research setting [13,15-17]. The stature of a human body normally varies over the course of the day. In upright sitting, stress both from body mass and gravity reduces disc height and therefore decreases body stature, termed 'stature loss' [16-18]. Stature recovery is the process of restoring disc height, possible because the disc has the ability to absorb fluid during periods of unloading the spine, in which the osmotic pressure within the disc is greater than the hydrostatic pressure from compressive loading $[16,17,19]$.

Many researchers have studied the magnitude of stature change between healthy and chronic low back pain participants [18,20-22]. Previous studies have demonstrated no difference in the magnitude of stature change after loading in participants with and without LBP [18,21,23,24]. Conversely, other researchers have reported that, after a short period of loading, degenerated discs show greater and faster creep deformation than healthy discs $[25,26]$. Hence, in persons with LBP, disc height loss may occur at higher rates at the beginning of the activity, that is, the largest disc height loss occurs within the first 
minutes after starting the work. Michel and Helander [22] reported the influence of chair type on stature change in healthy and low back pain persons. These researchers found a group of persons in a low back pain presented greater stature change when a seated task was performed, which was attributed to greater levels of spinal loading compared to a group of healthy persons.

Time of a day alters spinal systems and therefore has clinical implications [18,23,27]; researchers differ in their opinions about this. For example, Adams et al. [27] reported that disc bending stresses were increased by $300 \%$ in the morning compared to the evening; they concluded that in the morning there is increased risk of disc injury. Conversely, the discs have been reported as having poorer ability to manage the spinal load during activities in the afternoon; the discs have lower fluid content due to diurnal variation, and are therefore at greater risk of injury $[23,28]$.

The magnitude of stature change alters significantly over time; changes in stature occur in 2 phases (fast and slow). The rate of stature change is significantly greater when an individual rises in the morning, and gradually slows throughout the day [18]. Therefore, many researchers have studied the effects of time of day on changes in stature change after normal daily activities [22,23,28-32]. No statistically significant difference between stature loss from load activity in the morning and in the afternoon for healthy participants was reported in some previous studies [29-32]. This lack of significant difference was also reported in a study with chronic low back pain participants [23]. In contrast, other researchers have reported significant differences between morning and afternoon stature loss in healthy participants $[23,28]$ and in chronic low back pain participants [22].

Stature change response has been used to reflect the influence of daily routine work; through measurement at certain times of day on the same day [23,33,34], and between consecutive days $[24,35,36]$. However, it is difficult to interpret whether the stature change response recorded is truly due to the function of previous loading history or to the natural fluctuation of stature change response between days. Kanlayanaphotporn et al. [37] suggested that day-to-day variability of the stature change response should be investigated and understood to confidently state that the measured difference is the result of an intervention rather than either anticipated time of day effects or measurement variations.

To date, no investigation has reported the seated afternoon stature change response variability of participants with chronic low back pain. We hypothesised that day-to-day variability of stature change responses in the afternoon would be differ from the morning. These differences in variability may be affected by activities during the day or even by hydration status before measurements at each time of day. The current study aimed to investigate whether variability in seated stature change is affected by time of day and established the variability over 2 consecutive days in a sample of participants with chronic low back pain. Knowledge of such natural variations would enable researchers to determine whether an applied intervention was responsible for the detected changes in the stature response over 2 consecutive days in the morning and the afternoon.

\section{Materials and methods}

Design

A same-participant, test-retest design was used to assess the effect of time of day on the variability of stature change in participants with CLBP on 2 consecutive days. This study was conducted in the Research Center in Back, Neck, Other Joint Pain and Human Performance (BNOJPH) Laboratory at Khon Kaen University, Thailand. Ethical approval for the research was approved by the Human Research Ethics Committee (HE612281) of the University of Khon Kaen. The study was registered at clinicaltrials.in.th (registration number: TCTR20181009002).

\section{Participants}

Forty-four participants with CLBP were invited to take part in this study (see Table 1 for demographic information). They were recruited to participate in this study using a convenience sampling method via posters on bulletin boards at Khon Kaen University. CLBP was defined as pain between T12 and L5, which was not referred beyond the knees, and which had been present for at least 3 months [34,35,37]. Participants with CLBP were included if they were male or female aged between 20 - 39 years with normal BMI (18.5 - $\left.25 \mathrm{~kg} / \mathrm{m}^{2}\right)$ and reported mild levels of pain on the numerical rating scale (NPRS; 1 - 5 score). Participants were excluded if they: Had previous spinal surgery; were currently using medication that alters imbibition of water in the discs; had been identified with a medical condition that affected spinal soft tissues; were pregnant [35,37,39]. After having the protocol explained and any questions answered, all participants gave written, informed consent to participate in the study. Participants were offered US\$ 15.67 for their attendance and to cover travel costs. The sample size was 
calculated, following considerations of the standard deviations of stature change on 2 consecutive days in participants with CLBP [37], with an alpha of 0.05, effect size of 0.37, an optimal sample size at least 44 persons was selected to allow for a potential $10 \%$ dropout with corresponding data loss.

\section{Stadiometer}

Stature change response was measured using a seated stadiometer device (certified Thai petty-patent No. 5607; see Figure 1) [29,35]. The digimetic indicator shows real-time data on display and records data up to $5 \mathrm{~Hz}$ (ID-C 150, 1050 Digimetic Indicator, Manual No. 3061, Series No. 543, Mitutoyo, Kawasaki, Japan). This device is used to identify variations in stature change with a resolution of $\pm 0.006 \mathrm{~mm}$. The digimetic indicator was positioned at the top of the stadiometer, and used to measure the stature change (Figure 1(A)).

For head position control, the head support was adjustable to accommodate the participant's spinal posture. The distal end of the digimetic indicator was placed on the point indicating the vertex of each participant's skull that was initially marked by a waterproof pen. This enabled consistency of placement of the distal end of digimetic indicator throughout the experiment. The head position with eyes level was maintained by coaching participants to concentrate on a visual cue, a letter on the alphabet chart (A B C D) (Figure 1(C)), which was placed opposite at eye level [34,35].

For sitting position control, the wooden seat platform and the related footrest were adjustable so that the participant's ankle, knee and hip joints were positioned at $90^{\circ}$. Heels were placed at the back of the footrest. The sacral support was adjustable to accommodate the participant's spinal posture. A pillow was placed on the participant's lap to support their forearms at $90^{\circ}$ to their upper arms $[29,30,35]$.

For spinal control, spinal alignment was controlled by sensors placed on the 4 spinous processes of vertebrae; points identified were: Cervical (C4), Thoracic (T4), Thoracic (T12) and Lumbar (L3) $[29,34,35]$. These sensors were connected with a light diode feedback mechanism that was located opposite the seated participant. The sensors were used to confirm that the participant maintained the same sitting posture during measurement (Figure 1(B)).

The reliability of the seated stadiometer was tested by examining the reliability of the digimetic indicator and the researcher's (Rungthip Puntumetakul; RP) measurements. The intraclass correlation coefficient (ICC) was calculated. For the digimetic indicator device, the results showed very high reliability (ICC 1, 1=1.00). The intra-rater reliability of stature change measurements by the researcher (RP) was determined using 10 CLBP participants ( 5 males and 5 females). The results indicated excellent intra-rater reliability $(\operatorname{ICC} 3,1=0.98)$.

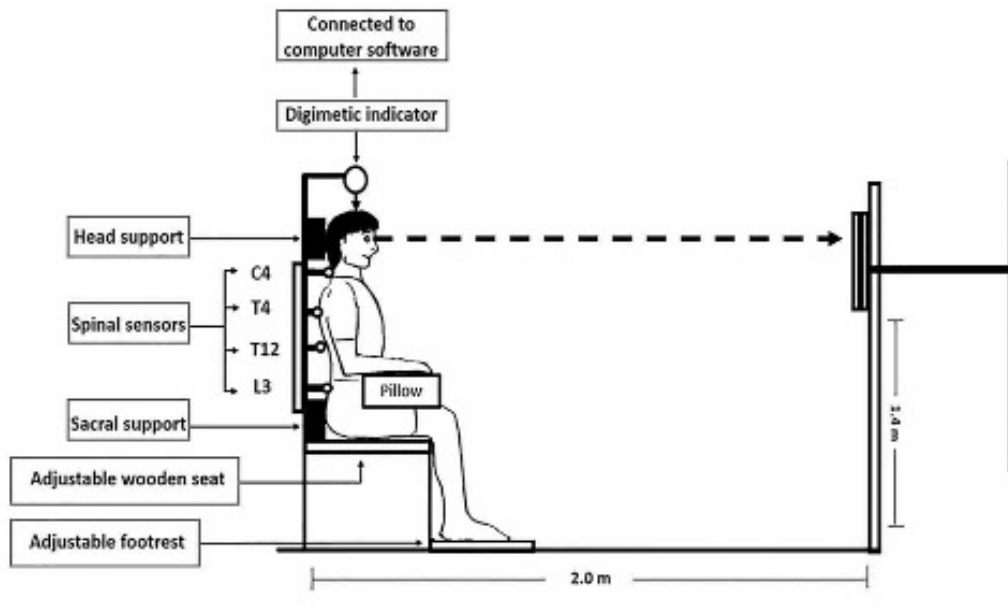

(A)

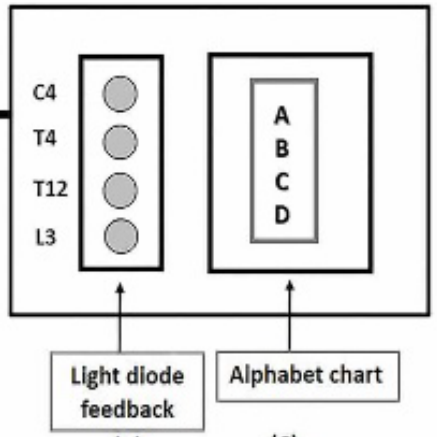

(B)
(C)

Figure 1 The device settings: (A) participant position in the seated stadiometry device, (B) light diode feedback and (C) alphabet letter. Source: Figure modified from Saiklang et al. [29]. 


\section{Pain measures}

Pain was used as an adjunct measure to quantify the inclusion criteria. Subjective pain measures were obtained using the numeric pain rating scale (NPRS) to assess pain over $24 \mathrm{~h}$ on a scale ranging from (0) 'no pain' to (10) 'worst possible pain'. NPRS pain score measures equated with pain intensity: Mild $(\leq 5)$, moderate $(6-7)$ and severe $(\geq 8)[38]$.

\section{Procedure}

The study procedure followed sequential steps (Figure 2). Forty-five participants with CLBP responded to the recruitment advertisement. The participants were screened for inclusion criteria by a physical therapist (RP). One participant was excluded as they reported experiencing low back pain $>5$ ie more than mild pain on the NRS. Forty-four participants were invited to attend an appointment at the experimental room on 5 days. On the first day, all the participants included in the study attended a familiarization session with the seated stadiometer device. They practised stepping in and out of the stadiometer until the SD of 10 repeated stature change measurements with a SD of $<0.5 \mathrm{~mm}$ was achieved [18,34]. All study participants were measured by Researcher (RP). The data were analysed by Researcher (Pongsatorn Saiklang; PS) who was blinded to participant details.

The participants were randomized to different sessions using a table of random numbers. A closed, opaque box was used to ensure session allocation confidentiality for measurements being taken in the morning (Session A) or afternoon (Session B). Participants assigned to Session A were measured in the morning in week 1 (on the second and third days), and in the afternoon in week 2 (on the fourth and fifth days). Participants assigned to Session B, had afternoon measurements in week 1 (on the second and third days) and morning measurements in week 2 (on the fourth and fifth days). The 2 measurement sessions, $\mathrm{A}$ and $\mathrm{B}$, were conducted 1 week apart.

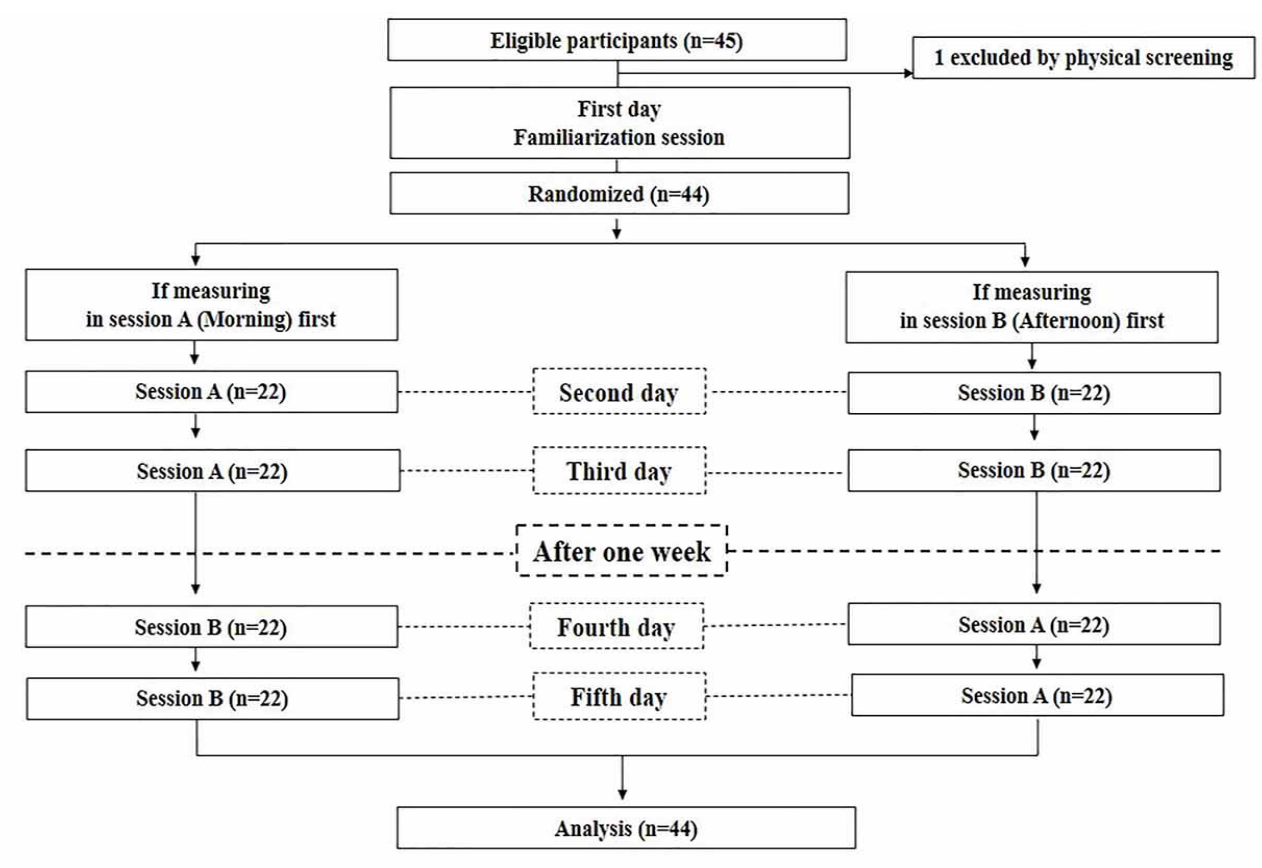

Figure 2 The study flowchart.

\section{Testing session A (morning)}

The participant attended between 8 - 10 am within an hour of the participants waking [23,29]. The participant was asked to adopt the Fowler's position for $20 \mathrm{~min}$ to reduce any irregular loading on the spine that might have occurred prior to coming to the experimental room [34,35]. Then, the participant was asked to attain the upright sitting position on the seated stadiometer, according to conditions described in the Stadiometer section, with the digimetic indicator in contact with the skull apex, marked by a waterproof pen. Their visual field was focused on an alphabet letter presented opposite them (Figure 1(C)). 


\section{Testing session B (afternoon)}

The participant was asked to attend between 2 - 4 pm [23,29]. All participants performed exactly the same procedure as in session A.

\section{Outcome measurement}

The magnitude of stature change (millimetres) was measured with a seated stadiometer. Participants were asked to remain in the same posture and not to speak during measurement in the seated stadiometer. All measurements were taken at the end of the expiration phase of the breathing cycle [40,41]. Each time of stature change measurement, involving average 75 data points, sampled over $15 \mathrm{~s}$, was considered at time 0 and the end of a 2-min interval. An average of 75 data points was needed to reduce uncontrolled movement and breathing patterns that might influence the measurement $[18,34,35]$.

\section{Data analysis}

Before beginning statistical analysis, The Shapiro-Wilk Test of normality was used to check the distribution of statue change measurement, and passed the assumption of normal distribution $(\mathrm{p}>0.05)$. Paired t-tests were used to examine the difference of stature change between sessions and over 2 consecutive days.

The standard error of measurement (SEM) was used to reflect the random variability of a single individual's scores on repetitive examination [42]. The SEM defines the range of magnitude of stature change that can be expected on repetitive examination [43]. The SEM was calculated using the equation from previous research [29]. Lower SEM scores relative to the means indicates smaller measurement variability [24].

The means of standard deviations (MeanSDs) between the 2 consecutive days of examination were considered in millimetres. MeanSDs were calculated by averaging the standard deviation of the stature change response between 2 days of the test in each person. Low MeanSDs scores relative to the means indicates smaller measurement variability [29,37].

The level of significance used for all statistical evaluations was $p$-value $<0.05$. All statistical analyses were achieved on SPSS version 19.

\section{Results and discussion}

Forty-four participants completed the study. All participants achieved the preferred level of repeatability for the stature change measurements $(\mathrm{SD} \leq 0.5 \mathrm{~mm})$. The demographic characteristics of the participants are presented in Table 1.

Table 1 Baseline characteristics of the participants.

\begin{tabular}{cccc}
\hline & $\begin{array}{c}\text { Combined }(\mathbf{N}=\mathbf{4 4}) \\
\text { Mean } \pm \text { SD }\end{array}$ & $\begin{array}{c}\text { Male }(\mathbf{N}=\mathbf{2 2}) \\
\text { Mean } \pm \text { SD }\end{array}$ & $\begin{array}{c}\text { Female }(\mathbf{N}=\mathbf{2 2}) \\
\text { Mean } \pm \text { SD }\end{array}$ \\
\hline Age (years) & $24.02 \pm 1.59$ & $24.23 \pm 1.57$ & $23.82 \pm 1.62$ \\
Standing height (cm) & $164.55 \pm 8.02$ & $170.55 \pm 4.73$ & $158.55 \pm 5.82$ \\
Sitting height (cm) & $85.36 \pm 5.17$ & $87.09 \pm 5.76$ & $83.64 \pm 3.91$ \\
Body mass (Kg) & $58.91 \pm 8.81$ & $66.00 \pm 6.13$ & $51.82 \pm 3.98$ \\
Body Mass Index (Kg/m $\left.{ }^{2}\right)$ & $21.66 \pm 1.88$ & $22.66 \pm 1.40$ & $20.66 \pm 1.78$ \\
Pain duration (month) & $8.77 \pm 8.04$ & $9.86 \pm 8.20$ & $7.68 \pm 7.92$ \\
Perceived Pain (score) & $3.11 \pm 0.89$ & $3.18 \pm 0.90$ & $3.05 \pm 0.90$ \\
\hline
\end{tabular}

Abbreviation: SD; standard deviation, kg; kilogram, cm; centimetre, $\mathrm{m}^{2}$; square meter.

The magnitude of stature change response at different times of day is presented in Figure 3. Response magnitude on 2 consecutive days was not significantly different (morning between day 1 and 2 $(-3.321 \mathrm{SD} 1.377 \mathrm{~mm}$ vs. $-3.419 \mathrm{SD} 1.294 \mathrm{~mm} ; p$-value $=0.636)$ and afternoon between day 1 and 2 $(-3.796 \mathrm{SD} 1.593 \mathrm{~mm}$ vs. $-3.516 \mathrm{SD} 1.384 \mathrm{~mm} ; p$-value $=0.084)$. Furthermore, the magnitude of stature change response between session $\mathrm{A}$ and $\mathrm{B}$ was not significantly different day 1 between morning and 
afternoon ( $-3.321 \mathrm{SD} 1.377 \mathrm{~mm}$ vs. $-3.796 \mathrm{SD} 1.593 \mathrm{~mm} ; p$-value $=0.077)$ and day 2 between morning and afternoon (-3.419 SD $1.294 \mathrm{~mm}$ vs. $-3.516 \mathrm{SD} 1.384 \mathrm{~mm} ; p$-value $=0.654)$.

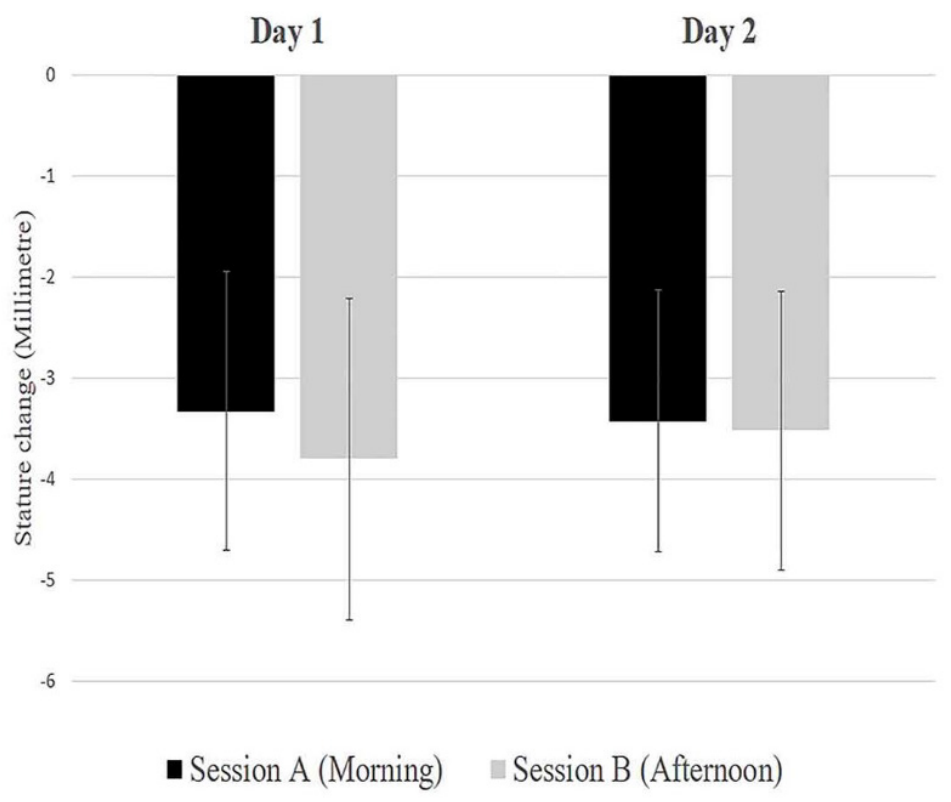

Figure 3 Magnitude of stature change response at different times of day in CBLP participants $($ Mean $\pm \mathrm{SD})$.

The variability of stature change responses at different times of day on 2 consecutive days in participants is presented in Table 2. The standard error of means (SEM) values was $0.985 \mathrm{~mm}$ in the morning and $1.149 \mathrm{~mm}$ in the afternoon. The means of standard deviations (MeanSD) values were 0.772 and $0.863 \mathrm{~mm}$ in the morning and in the afternoon, respectively.

Table 2 Variability of stature change response at different times of day on 2 consecutive days in CLBP participants $(\mathrm{N}=44)$.

\begin{tabular}{clc}
\hline Session & MeanSDs & SEM \\
\hline Session A (morning) & $0.772 \mathrm{~mm}$ & $0.985 \mathrm{~mm}$ \\
Session B (afternoon) & $0.863 \mathrm{~mm}$ & $1.149 \mathrm{~mm}$ \\
\hline
\end{tabular}

Abbreviation: MeanSDs; Means of standard deviations, SEM; Standard error of measurement, mm; millimetre

\section{Discussion}

The results demonstrated no difference in the magnitude of stature change response between sessions (morning and afternoon) and over 2 consecutive days (Day 1 and 2). These results are similar to those from previous studies, which reported no difference between morning and afternoon measurements of stature in CLBP participants [23]. There are 2 possible explanations as to why the magnitude of stature change showed no difference between morning and afternoon. Firstly, the measurement method combined standardised loading and positioning trials; so, it is not surprising that the magnitude of stature change was similar between morning and afternoon measurements [30]. Secondly, the participants sat after lying in the unload position for $20 \mathrm{~min}$ (Fowler's position). Subsequently, the rate of stature change between morning and afternoon measurements represented the same rate (fast phase) of stature change caused by liquid being expelled from the disc in response to body weight $[17,18]$. Therefore, the magnitude of stature change showed no difference between morning and afternoon measurements. 
The current study investigated the effect of time of day (morning and afternoon) on stature change response variability in participants with CLBP on 2 consecutive days. In previous studies, Kanlayanaphotporn et al. [37] investigated the stature change response on 2 consecutive days. However, all their data were collected in the morning. The current study is the first study to attempt to investigate the variability of stature change response in the afternoon. The SEM value was $0.985 \mathrm{~mm}$ in the morning and $1.149 \mathrm{~mm}$ in the afternoon. The MeanSD values were $0.772 \mathrm{~mm}$ in the morning and 0.863 in the afternoon (Table 2). In the afternoon, the results of measures may be affected by activities earlier in the day prior to measurement $[16,18,44]$. This factor might impact the fluid content of the discs leading to variability of day-to-day stature change $[16,18,29,44]$. The results of current study are supported by previous research [29]. In that study, the investigators measured the effect of time of day (morning vs. afternoon) on stature change response variability in healthy participants on 2 consecutive days. They reported that in the afternoon $(\mathrm{SEM}=1.128 \mathrm{~mm}$, MeanSDs $=0.907 \mathrm{~mm})$, there is a higher level of variability of stature change response over 2 consecutive days than in the morning (SEM $=0.886 \mathrm{~mm}$, MeanSDs $=0.667 \mathrm{~mm}$ ) [29].

The findings suggest that it is important to control the time at which stature change investigations are conducted. For meaningful comparisons in chronic low back pain individuals, a required response should be in excess of $0.985 \mathrm{~mm}$ in the morning and $1.149 \mathrm{~mm}$ in the afternoon between consecutive days. This study found useful information about participants with CLBP. One limitation is that participants were young, with a small age range (aged 20 - 26 years). Consequently, the results might not be applicable to other age groups. Further research is required to study the result of sitting on the variability and magnitude of stature change measured in an older age group to confidently confirm the value of stature change.

\section{Conclusions}

These findings suggest that it is important to control the time at which stature change investigations are conducted. For an intervention to have influenced the stature change response in chronic low back pain participants, a response in excess of $0.985 \mathrm{~mm}$ in the morning and $1.149 \mathrm{~mm}$ in the afternoon between consecutive days is required. This will be useful information for future investigations on this topic.

\section{Acknowledgements}

The authors thank the participants for their willingness to participate in this study, The Royal Golden Jubilee (RGJ) Ph.D. Programme. The Thailand Research Fund (TRF), Thailand (PHD/0090/2558). Research Center in Back, Neck, Other Joint Pain and Human Performance (BNOJPH), Khon Kaen University, Thailand.

\section{References}

[1] P Keawduangdee, R Puntumetakul, M Swangnetr, W Laohasiriwong, D Settheetham, J Yamauchi and R Boucaut. Prevalence of low back pain and associated factors among farmers during the rice transplanting process. J. Phys. Ther. Sci. 2015; 27, 2239-45.

[2] L Manchikanti, V Singh, FJE Falco, RM Benyamin and JA Hirsch. Epidemiology of low back pain in adults. Neuromodulation 2014; 17, 3-10.

[3] C Montakarn and N Nuttika. Physical activity levels and prevalence of low back pain in Thai callcenter operators. Indian J. Occup. Environ. Med. 2016; 20, 125-8.

[4] E Sitthipornvorakul, P Janwantanakul and V Lohsoonthorn. The effect of daily walking steps on preventing neck and low back pain in sedentary workers: A 1-year prospective cohort study. Eur. Spine J. 2015; 24, 417-24.

[5] RD Meucci, AG Fassa and NM Faria. Prevalence of chronic low back pain: Systematic review. Rev. Saude Publ. 2015; 49, 73.

[6] F Balagué, AF Mannion, F Pellisé and C Cedraschi. Non-specific low back pain. Lancet 2012; 379, 482-91.

[7] S Jiménez-Sánchez, C Fernández-De-Las-Peñas, P Carrasco-Garrido, V Hernández-Barrera, C Alonso-Blanco, D Palacios-Ceña and R Jiménez-García. Prevalence of chronic head, neck and low back pain and associated factors in women residing in the Autonomous Region of Madrid (Spain). Gac. Sanit. 2012; 26, 534-40. 
[8] G Olafsson, E Jonsson, P Fritzell, O Hägg and F Borgström. A health economic lifetime treatment pathway model for low back pain in Sweden. J. Med. Econ. 2017; 20, 1281-9.

[9] F Hanna, RN Daas, TJ El-Shareif, HH Al-Marridi, ZM Al-Rojoub and OA Adegboye. The relationship between sedentary behavior, back pain, and psychosocial correlates among university employees. Front. Publ. Health 2019; 7, 80.

[10] P Waongenngarm, BS Rajaratnam and P Janwantanakul. Internal oblique and transversus abdominis muscle fatigue induced by slumped sitting posture after 1 hour of sitting in office workers. Saf. Health Work 2016; 7, 49-54.

[11] NT Hadgraft, GN Healy, N Owen, EA Winkler, BM Lynch, P Sethi, EG Eakin, M Moodie, AD Lamontagne, G Wiesner, L Willenberg and DW Dunstan. Office workers' objectively assessed total and prolonged sitting time: Individual-level correlates and worksite variations. Prev. Med. Rep. 2016; 4, 184-91.

[12] GG Billy, SK Lemieux and XM Chow. Changes in lumbar disk morphology associated with prolonged sitting assessed by magnetic resonance imaging. PM R: J. Inj. Funct. Rehabil. 2014; 6, $790-5$.

[13] JCJ Fryer, JA Quon and FW Smith. Magnetic resonance imaging and stadiometric assessment of the lumbar discs after sitting and chair-care decompression exercise: A pilot study. Spine J. 2010; 10, 297-305.

[14] DL Wang, SD Jiang, LY Dai. Biologic response of the intervertebral disc to static and dynamic compression in vitro. Spine (Phila Pa 1976). 2007; 32, 2521-8.

[15] MM Munster, JM Brismée, PS Sizer, K Browne, B Dewan, A Litke, JL Pape and S Sobczak. Can 5 minutes of repetitive prone press-ups and sustained prone press-ups following a period of spinal loading reverse spinal shrinkage? Physiother. Theor. Pract. 2019; 35, 259-67.

[16] H Schmidt, S Reitmaier, F Graichen and A Shirazi-Adl. Review of the fluid flow within intervertebral discs - How could in vitro measurements replicate in vivo? J. Biomech. 2016; 49, 3133-46.

[17] PA Vergroesen, AJVD Veen, KS Emanuel, JHV Dieën and TH Smit. The poro-elastic behaviour of the intervertebral disc: A new perspective on diurnal fluid flow. J. Biomech. 2016; 49, 857-63.

[18] EL Healey, AM Burden, IM McEwan and NE Fowler. Diurnal variation in stature: Do those with chronic low-back pain differ from asymptomatic controls? Clin. Biomech. (Bristol, Avon). 2011; 26, 331-6.

[19] JL Pape, JM Brismée, PS Sizer, OC Matthijs, KL Browne, BM Dewan and S Sobczak. Increased spinal height using propped slouched sitting postures: Innovative ways to rehydrate intervertebral discs. Appl. Ergon. 2018; 66, 9-17.

[20] NE Fowler, CDL Rodacki and AL Rodacki. Spinal shrinkage and recovery in women with and without low back pain. Arch. Phys. Med. Rehabil. 2005; 86, 505-11.

[21] CL Rodacki, NE Fowler, AL Rodacki and K Birch. Stature loss and recovery in pregnant women with and without low back pain. Arch. Phys. Med. Rehabil. 2003; 84: 507-12.

[22] DP Michel and MG Helander. Effects of two types of chairs on stature change and comfort for individuals with healthy and herniated discs. Ergonomics 1994; 37, 1231-44.

[23] EL Healey, AM Burden, IM McEwan and NE Fowler. Stature loss and recovery following a period of loading: effect of time of day and presence or absence of low back pain. Clin. Biomech. (Bristol, Avon). 2008; 23, 721-6.

[24] EL Healey, NE Fowler, AM Burden and IM Mcewan. The influence of different unloading positions upon stature recovery and paraspinal muscle activity. Clin. Biomech. (Bristol, Avon). 2005; 20, 365-71.

[25] TS Keller, DM Spengler and TH Hansson. Mechanical behavior of the human lumbar spine. I. Creep analysis during static compressive loading. J. Orthop. Res. 1987; 5, 467-78.

[26] W Koeller, F Funke and F Hartmann. Biomechanical behavior of human intervertebral discs subjected to long lasting axial loading. Biorheology 1984; 21, 675-86.

[27] MA Adams, P Dolan, WC Hutton and RW Porter. Diurnal changes in spinal mechanics and their clinical significance. J. Bone Joint Surg. Br. 1990; 72, 266-70.

[28] J Wilby, K Linge, T Reilly and JD Troup. Spinal shrinkage in females: circadian variation and the effects of circuit weight-training. Ergonomics 1987; 30, 47-54.

[29] P Saiklang, R Puntumetakul, MN Swangnetr and R Boucaut. Effect of time of day on height loss response variability in asymptomatic participants on two consecutive days. Ergonomics 2019; 62, $1542-50$. 
[30] R Puntumetakul, P Trott, M Williams and I Fulton. Effect of time of day on the vertical spinal creep response. Appl. Ergon. 2009; 40, 33-8.

[31] I Althoff, P Brinckmann, W Frobin, J Sandover and K Burton. An improved method of stature measurement for quantitative determination of spinal loading. Application to sitting postures and whole body vibration. Spine (Phila Pa 1976). 1992; 17, 682-93.

[32] TK Foreman and JD Troup. Diurnal variations in spinal loading and the effects on stature: A preliminary study of nursing activities. Clin. Biomech. (Bristol, Avon). 1987; 2, 48-54.

[33] DA Gerke, J Brismée, PS Sizer, GS Dedrick and CR James. Change in spine height measurements following sustained mid-range and end-range flexion of the lumbar spine. Appl. Ergon. 2011; 42, 331-6.

[34] R Kanlayanaphotporn, P Trott, M Williams and I Fulton. Effects of chronic low back pain, age and gender on vertical spinal creep. Ergonomics 2003; 46, 561-73.

[35] P Saiklang, R Puntumetakul, MN Swangnetr and R Boucaut. The immediate effect of the abdominal drawing-in maneuver technique on stature change in seated sedentary workers with chronic low back pain. Ergonomics 2021; 64, 55-68.

[36] P Saiklang, R Puntumetakul, J Selfe and G Yeowell. An evaluation of an innovative exercise to relieve chronic low back pain in sedentary workers. Hum. Factors 2021. https://doi.org/10.1177\%2F0018720820966082

[37] R Kanlayanaphotporn, M Williams, I Fulton and P Trott. Reliability of the vertical spinal creep response measured in sitting (asymptomatic and low-back pain subjects). Ergonomics 2002; 45, 240-7.

[38] MA Boonstra, RE Stewart, AJA Köke, RFA Oosterwijk, JL Swaan, KMG Schreurs and HRS Preuper. Cut-off points for mild, moderate, and severe pain on the numeric rating scale for pain in patients with chronic musculoskeletal pain: Variability and influence of sex and catastrophizing. Front. Psychol. 2016; 7, 1466.

[39] S Lewis, P Holmes, S Woby, J Hindle and N Fowler. Changes in muscle activity and stature recovery after active rehabilitation for chronic low back pain. Man. Ther. 2014; 19, 178-83.

[40] C Rodacki, LNE Fowler, ALF Rodacki and K Birch. Technical note: Repeatability of measurement in determining stature in sitting and standing postures. Ergonomics 2001; 44, 1076-85.

[41] EN Corlett, JAE Eklund, T Reilly and JDG Troup. Assessment of workload from measurements of stature. Appl. Ergon. 1987; 18, 65-71.

[42] WG Hopkins. Measures of reliability in sports medicine and science. Sports Med. 2000; 30, 1-15.

[43] LG Portney and MP Watkins. Foundations of clinical research: Applications to practice. $3^{\text {rd }}$ ed. FA Davis Company, Philadelphia, 2015, p.608.

[44] J Stothart and SM Mcgill. Stadiometry: On measurement technique to reduce variability in spine shrinkage measurement. Clin. Biomech. (Bristol, Avon). 2002; 15, 546-8. 